\title{
Designing and Implementing a Comparative Effectiveness Study of Two Strategies for Delivering High Quality CHD Prevention: Methods and Participant Characteristics for the Heart to Health Study
}

\author{
Stacey L. Sheridan, MD, MPH ${ }^{a, b}, c$, Lindy B. Draeger, MPH ${ }^{b}$, Michael P. Pignone, MD, \\ MPH $^{\mathrm{a}, \mathrm{c}}$, Philip D. Sloane, $\mathbf{M D}^{\mathrm{c}, \mathrm{d}}$, Carmen Samuel-Hodge, PhD, $\mathbf{R D}^{\mathrm{b}, \mathrm{e}}$, Eric A. Finkelstein, \\ PhD, MA, MHA ${ }^{f}$, Ziya Gizlice, PhD $^{b}$, Maihan B. Vu, DrPH, MPH ${ }^{b}$, Daniel P. Gitterman, PhDg, \\ Shrikant I. Bangdiwala, PhD ${ }^{b, c, h}$, Katrina E. Donahue, MD, MPH ${ }^{c, d}$, Kelly Evenson, PhD, MSi, \\ Alice S. Ammerman, DrPH, RD ${ }^{b, e}$, and Thomas C. Keyserling, MD, MPH ${ }^{a, b}$ \\ aDivision of General Medicine and Clinical Epidemiology, CB 7110, University of North Carolina, \\ Chapel Hill, NC 27599 \\ ${ }^{b}$ Center for Health Promotion and Disease Prevention, CB 7426, University of North Carolina, \\ Chapel Hill, NC 27599 \\ ${ }^{\circ}$ Cecil G. Sheps Center for Health Services Research, CB 7590, University of North Carolina, \\ Chapel Hill, NC 27599 \\ dDepartment of Family Medicine, CB 7595, University of North Carolina, Chapel Hill, NC 27599 \\ eDepartment of Nutrition, CB 7461, University of North Carolina, Chapel Hill, NC 27599 \\ ${ }^{f} H$ Health Services and Systems Research Program, Duke-National University of Singapore \\ Graduate Medical School, Singapore \\ 9Department of Public Policy, CB 3435, University of North Carolina, Chapel Hill, NC 27599 \\ hDepartment of Biostatistics, CB 7420, University of North Carolina, Chapel Hill, NC 27599 \\ 'Department of Epidemiology, CB 8050, University of North Carolina, Chapel Hill, NC 27599
}

\begin{abstract}
Background-Although lifestyle and medications are effective for coronary heart disease (CHD) risk reduction, few studies have examined the comparative effectiveness of various strategies for delivering high quality CHD risk reduction. In this paper, we report on the design and baseline characteristics of participants for just such a trial.
\end{abstract}

\footnotetext{
(C) 2013 Elsevier Inc. All rights reserved.

Corresponding author (contact and reprints): Stacey L Sheridan, 5039 Old Clinic Building, CB 7110, University of North Carolina, Chapel Hill, NC, 27599, Phone: 919-966-2276, Fax: 919-966-2274, sls593@ med.unc.edu.

Publisher's Disclaimer: This is a PDF file of an unedited manuscript that has been accepted for publication. As a service to our customers we are providing this early version of the manuscript. The manuscript will undergo copyediting, typesetting, and review of the resulting proof before it is published in its final citable form. Please note that during the production process errors may be discovered which could affect the content, and all legal disclaimers that apply to the journal pertain.
} 
Methods-We conducted a randomized trial of the same lifestyle and medication intervention delivered in two alternate formats: counselor-delivered or web-based. The trial was conducted at 5 diverse practices in a family medicine research network and included men and women age 35-79 who were at high risk of CHD events based on 10-year predicted Framingham risk of $\geq 10 \%$ or a known history of cardiovascular disease. After individual-level randomization, participants in both arms received a decision aid plus four intensive intervention visits and 3 maintenance visits over 12 months. The primary outcome was change in 10-year predicted CHD risk among patients without prior cardiovascular disease. Secondary outcomes, measured among all participants, included changes in CHD risk factors, cost-effectiveness, and acceptability at 4 and 12-month follow-up.

Results-We randomized 489 eligible patients: 389 without and 100 with a known history of cardiovascular disease. Mean age was 62.3. 75\% were white, 25\% African American. $45 \%$ had a college education. 88\% had health insurance. Mean 10-year predicted CHD risk was 16.9\%.

Conclusion-We have successfully recruited a diverse sample of practices and patients that will provide a rich sample in which to test the comparative effectiveness of two strategies to implement high quality CHD prevention.

\section{Keywords}

Coronary Heart Disease; Prevention; Counseling; Therapy/Computer-Assisted; Evidence-Based Practice

\section{Introduction}

Coronary heart disease (CHD) is responsible for one-third of deaths in the United States and is one of the leading causes of premature, permanent disability [1]. This high medical and financial burden has made CHD a critical public health issue for the United States and prompted national campaigns to improve prevention of CHD [2] by reducing the development of CHD risk factors (primordial prevention) and by treating elevated risk factors in those without and with known CHD (primary and secondary prevention, respectively).

Fortunately, lifestyle changes and medication are effective for CHD risk reduction. High quality observational data has shown that a healthful lifestyle (including not smoking, maintaining a healthy weight, getting regular physical activity, eating a healthy diet, and consuming alcohol only in moderation) are associated with rates of CHD that are $80 \%$ lower than people who do not demonstrate these behaviors [3]. Additionally, a recent randomized trial suggests a $30 \%$ reduction in major cardiovascular events with a diet high in fruits, vegetables, and fish, supplemented with nuts, or olive oil [4]. Furthermore, multiple high quality randomized trials and meta-analyses have demonstrated statins, hypertension medicines, and aspirin each reduce the risk of CHD events (myocardial infarction (MI) and CHD death) by $25-30 \%$ [5-12].

Given clear evidence of the benefits of lifestyle changes and medication for CHD risk reduction, what is at issue is not what needs to be done to reduce CHD risk, but how to do it effectively and efficiently. Investigators and practitioners have tried a host of interventions 
to reduce CHD risk. These fall broadly into 3 categories: pharmacist or educator led programs for lifestyle and medication counseling [13-15]; interactive health technology (e.g. computerized education, decision aids, and counseling; and automated telephone calls) $[16,17]$; and referrals to community counseling programs (e.g. nutrition counseling, smoking quit lines) [18, 19]. All have shown some success in primary care settings, but few have jointly addressed both lifestyle changes and medications [14, 20,21]. Additionally, few have been comparatively tested to determine their relative effectiveness, cost effectiveness, and acceptability.

In this paper, we present the protocols and participant characteristics for a study comparing the effectiveness of the same lifestyle and medication intervention for CHD prevention delivered in two alternate formats: counselor-delivered or web-based. Given recent national interest in both comparative effectiveness research $[22,23]$ and strategies to improve the delivery of clinical care [24], we believe a detailed description of the study design, and ultimately the results, should be of interest to a wide range of stakeholders (researchers, practicing health professionals, patients, and payers).

\section{Methods}

\subsection{Study overview}

To assess the comparative effectiveness of two alternate formats of CHD prevention (counselor-delivered vs. web-based), we conducted a randomized trial at 5 diverse family medicine practices located in central North Carolina (see Figure 1). Our primary intent was to determine the interventions' effect in patients without prior cardiovascular disease (CVD; previous MI, coronary artery bypass surgery, coronary angioplasty or stent placement, transient ischemic attack or stroke or known peripheral vascular disease or angina). We secondarily tested our intervention in a smaller sample of patients with known CVD to generate hypotheses about whether counseling and web-interventions work similarly or differently in secondary prevention patients. Study outcomes included effectiveness, costeffectiveness, and acceptability assessed at 4- and 12-month follow-up. The University of North Carolina at Chapel Hill's Biomedical Institutional Review Board (IRB) approved and monitored this study. The trial was registered at clinical trials.gov (NCT01245686).

\subsection{Stakeholder engagement}

To inform development and future dissemination of our intervention, we convened a single focus group of health care decision makers in North Carolina. Participants were purposively sampled to represent key-stakeholders in CHD prevention and included 5 men and 2 women representing the North Carolina (NC) Health Quality Alliance, the NC Division of Public Health, the NC Foundations for Advanced Health Program, the American Heart Association, Community Care of NC, and the Veterans Administration (VA). The focus group was conducted by the Director for Formative Research at UNC's Center for Health Promotion and Disease Prevention and content followed a structured discussion guide. The session was digitally recorded, transcribed, and checked for accuracy. Then a key point analysis was performed. Decision makers emphasized the importance of low cost, effective interventions that are practical, acceptable to end-users, and implementable with the resources available in 
practice. They also emphasized the need to target multiple (rather than single) risk factors; target both primary and secondary prevention; and teach lifestyle and medication management skills applicable to a range of disease prevention and treatment strategies. We incorporated this input throughout our trial development to help us design our counselordelivered and web-based interventions, collect data that would be of interest to major stakeholders, and increase the likelihood of future dissemination.

\subsection{Setting}

We conducted our study in practices affiliated with the North Carolina Family Medicine Research Network (NC-FM-RN). The NC-FM-RN is a practice-based research network that aims to improve primary care through research and dissemination of evidence-based practices. It includes over 63 practices that are representative of North Carolina's geographic and ethnic diversity [25]. Practices include 29 private practices, 22 academic practices, and 12 community health centers with over 500 practicing clinicians serving 801,000 patients.

We designed our recruitment strategy to ensure a mix of practice types and participants. Sampling initially proceeded through a process of optimized random sampling [26]to ensure a sample representative of the network. However, too few practices met specified sampling criteria to proceed with this approach, thus, we purposively sampled practices according to the following criteria: at least 2 practices with a patient population with $>20 \%$ AfricanAmericans; and at least 2 practices affiliated with a community health center. Ultimately, we recruited two community health centers, two private practices, and one private practice with an academic affiliation to participate in our study. Characteristics of included practices are shown in Table 1.

\subsection{Participant screening}

We recruited patients from each of the 5 participating practices to take part in our study. Recruitment occurred through a combination of daily chart reviews, self-referrals, and clinician referrals. Within each practice, health educators conducted daily chart reviews of patients scheduled for routine office visits and advertised for participants with waiting room flyers. Clinicians also referred patients felt to be appropriate candidates for the study. Inclusion criteria were assessed via chart review and included: established patients at participating practices (seen for an office visit within the past 2 years), age 35-79, and at high risk for CHD (angina, MI, or CHD death) defined by a Framingham risk score of $\geq$ $10 \%$ [27] or known CVD. For potentially eligible patients, clinicians completed a clinician enrollment form. On this form, clinicians indicated whether patients should be excluded based on treatment of psychosis; history of alcohol or substance abuse in the last 2 years; pregnancy, breastfeeding, or intention to get pregnant during the ensuing 18 months; primary language not English; history of malignancy, other than non-melanoma skin cancer, that had not been in remission or cured surgically for $>5$ years; estimated creatinine clearance $<30 \mathrm{ml} / \mathrm{min}$; or recent history of serious hypoglycemia (requiring medical attention in the past year). Clinicians also indicated whether or not they approved patient participation in the study and specifically participation in the physical activity portion of the study. 


\subsection{Participant enrollment}

With clinician approval, patients were seen by study staff for a formal screening and enrollment visit. During the visit, study staff obtained written informed consent, confirmed whether or not participants had a prior history of CVD, screened participants for potential bleeding risk associated with aspirin, and collected additional data by standard methods across practices to assess CHD risk (e.g. blood pressure, blood specimen for lipids) and rule out significant renal dysfunction. If participants had known CVD or remained at sufficiently high risk of predicted CHD events ( $\geq 10 \%$ ) based on data collected at the enrollment visit, they continued participation in the study and were contacted by telephone to assess additional baseline measures. They then returned for their first intervention visit.

\subsection{Randomization}

At the first intervention visit and prior to initiation of the intervention, we randomized participants to either the counselor-delivered or web-based interventions. Randomization was computer-generated, used 1:1 allocation, and was stratified by study site (5 sites) and CHD risk (3 groups: no CVD with CHD risk of 10-19\%, no CVD with CHD risk $\geq 20 \%$, known CVD). It was also blocked (with block size of 2) to ensure balance between study arms among participants enrolled at each site and within CHD risk stratum. Random assignment was concealed in an online participant tracking system and revealed to study staff only after they indicated that participants had completed baseline study measures.

\subsection{Intervention}

Our intervention included a combined lifestyle and medication adherence intervention delivered in two alternate formats: counselor-delivered or web-based. Participants in both arms received a computerized decision aid and then either 7 sessions of counseling from a counselor or 7 sessions of interactive tailored messaging on the web (up to 5.5 hours of interventional contact; see Figure 2). In designing the intervention, our goal was to deliver the same content in both formats. Thus, we designed the scripted counseling and written materials in the counselor arm to match the text of the web-based intervention and used the same sequencing of materials for both interventions. Given limited resources, the intervention was developed only in English. Details about our intervention are provided below; further detail is provided in Appendix A.

2.7.1. The evidence for our interventions-The evidence for the diet and physical activity components of our interventions was drawn from the literature used in creation of the New Leaf intervention [28-31] and updated with 1) the best available evidence on the relative risk reductions associated with eating a healthy diet (20-40\%) and being physically active (10-20\%) and 2) recent evidence supporting a focus on dietary fat quality (i.e. eating polyunsaturated fats rather than reducing total fat content)[32-38]. The evidence for the medication and smoking cessation intervention components was drawn from the evidencebased Heart to Heart intervention [39] and updated to include new information on aspirin and statin side effects from nationally representative cohort data [40, 41]. A stroke risk calculator was also added, but only for women who indicated an interest in exploring aspirin as an option to reduce their risk, given that recent meta-analyses showed, on average, no 
benefit of aspirin for CHD risk reduction in women, but clear benefit for stroke risk reduction in women $[42,43]$.

2.7.2. Decision aid-We developed two versions of the decision aid: one for participants without CVD but at high risk for CHD events and one for participants with known CVD. Both decision aids were modeled after the Heart to Heart decision aid that we previously developed and tested $[39,44]$.

For participants with no history of CVD but who were at high risk of CHD events, the decision aid: 1) calculated participants' 10-year CHD risk using a continuous Framingham equation [45], 2) educated participants about their CHD risk, their personal risk factors, and the pros and cons of possible risk-reducing strategies including changing diet, increasing physical activity, stopping smoking, starting aspirin, and starting or increasing blood pressure medicine or cholesterol medicine, 3) showed participants how much their CHD risk might be reduced by any single or combination of lifestyle and medication risk reducing strategies, and 4) encouraged participants to select the strategies(s) they wish to pursue to reduce their risk after encouragement to consider their personal values. Although offering patients choices among risk reducing strategies might seem controversial, this approach helps patients to match the intensity of their CHD prevention efforts with their concerns for safety, cost, and the time commitment for treatments [46]. Further, in prior studies, it has been associated with increased adherence and reduced CHD risk [39].

For those with known CVD, the decision aid: 1) described the increased risk for future CHD events (20\% based on meta-analyses) [47, 48], 2) educated patients about the pros and cons of available risk reducing strategies including changing diet, increasing physical activity, stopping smoking, taking aspirin, and taking or increasing blood pressure medicine or cholesterol medicine, and 3) recommended pursuing all available risk-reducing strategies.

\subsubsection{Counselor-delivered and web-based intervention sessions-In either}

format, interventions included 4 intensive sessions (each up to 60 minutes in duration depending on participants' individual pace in the web or counselor-delivered sessions) at monthly intervals, followed by 3 maintenance sessions (each 15-30 minutes in duration) delivered at 2 month intervals. The first intensive visit was always conducted in the participating clinic. Subsequent visits could occur remotely (by phone for those in the counselor arm or at home via the web for those in the web-arm) if the participant preferred. All counseling was conducted by trained health counselors, who held degrees in nursing, social work, or nutrition.

The first intensive session opened with self-assessment of lifestyle and barriers to each chosen risk-reducing strategy and continued with content specific education on diet, physical activity, smoking cessation, or medication adherence (see Appendix A). For those who chose to work on diet, it also included tips to circumvent self-identified barriers to risk reduction (see Appendix A) and creation of first steps toward self-identified actionable goals. First steps specified exactly what participants would do, when they would get started, and what additional resources they needed to start. All subsequent sessions included the same basic content regardless of chosen risk reducing strategy: they opened with a check-in 
on progress toward goals, continued with education and tips to circumvent barriers, and finished with identification of new first steps (see Figure 2). All participants received ancillary resources including a Heart to Health cookbook, pedometers and physical activity logs for self-monitoring of exercise, and an illustrated community resource guide that specified local resources for healthy eating (e.g. farmers markets) and physical activity (e.g. walking trails).

The content of maintenance sessions was tailored according to participants' success in adhering to their chosen risk reducing strategy(s), which was assessed at the beginning of the first maintenance visit. Messages focused on the following basic topics: relapse prevention, problem solving, and lessons for long-term maintenance. In the relapse prevention session, participants learned to identify and handle "risky" situations in which individuals are likely to slip into old behaviors. They also got tips on what to do if they slipped (e.g. keep a positive attitude, regroup, seek support from others). In the problem solving session, participants learned to define the problem, brainstorm solutions, choose the best possible solutions, and plan for implementation of their solutions. Finally, in the session on lessons for long-term maintenance, participants were encouraged to renew their commitment to heart disease prevention; apply relapse prevention, problem solving, and first step planning; monitor their success (using log books, pedometers, blood pressure and cholesterol checks, or risk recalculation); and build a support system for success.

2.7.4. Pre-testing the intervention-To ensure that our interventions were understandable and usable, we performed cognitive and usability testing on each component of the intervention. Testing was conducted until all content and functionality had been reviewed by at least two individuals and the research team felt confident that the intervention was understood and usable. This required testing in 9 individuals; all met inclusion criteria for our trial. To alleviate respondent burden, each participant gave input on only a subset of intervention components. However, we assured that each component was reviewed by at least two individuals. Iterative revisions of intervention content were performed based on this pre-testing.

\subsection{Outcomes}

We measured 3 types of outcomes in this study: effectiveness, acceptability, and costeffectiveness. Effectiveness outcomes were divided into 3 categories. Our primary effectiveness outcome was change in 10-year predicted CHD risk in participants without known CVD. Secondary outcomes were measured in participants both without and with known CVD and included changes in blood pressure, cholesterol, aspirin use, medication adherence, dietary behaviors, and physical activity. Tertiary outcomes were measured in all participants and included weight, body mass index (BMI), general quality of life and outcomes related to possible harms (liver function tests (LFTs), and creatinine (Cr)). All outcomes were measured at both 4 months (primary timeframe) and 12 months in both study arms. The details of measurements are described below; an overview is provided in Table 2. 


\subsection{Measures}

\subsubsection{Effectiveness Measures}

10-year predicted CHD risk (primary outcome): We measured 10-year predicted global CHD risk at baseline, 4-month, and 12-month follow-up, using a well-validated Framingham risk equation [45]. As we've done in our prior work [39], we assumed that the benefits of lifestyle and medication are reasonably captured by entering revised risk factor data into the Framingham equation. Because aspirin use was not accounted for by the Framingham equation, we modeled the effects of aspirin on CHD risk using a 23\% risk reduction for men and a $0 \%$ reduction for women [49]. Patients with diabetes were not considered to have a risk equivalent to those with known CVD, thus we calculated CHD risk for patients with diabetes.

CHD risk factors (secondary outcomes): We measured CHD risk factors at baseline, 4 month, and 12-month follow-up, through a combination of measures applied using welldefined protocols. We measured blood pressure using a non-invasive oscillometric automatic monitor (Omron HEM-907) after the patient has been seated for at least 5 minutes. We averaged three measurements taken at one minute intervals, and defined hypertension as a systolic measurement $>140 \mathrm{~mm} \mathrm{Hg}$. We measured serum total and HDL cholesterol using enzymatic testing and direct LDL cholesterol using enzymatic/ spectrophotometric testing without sample pre-treatment (LabCorp, Burlington, NC). We measured aspirin use by self-report (yes/no) with confirmation of reported aspirin use by serum thromboxane level (Laboratory for Clinical Biochemistry Research, University of Vermont); serum thromboxane levels of $<500 \mathrm{pg} / \mathrm{ml}$ were considered indicative of aspirin use based on prior experience of the laboratory and the results of pilot testing in 10 patients ( 5 with and 5 without known aspirin use). We measured smoking status by self-report (>100 cigarettes: yes/no) with confirmation by urine dipstick using the NicAlert test strips (Jant Pharmacal; Encino, CA) in those who reported quitting. A test strip measure of 3 or higher (cotinine concentration $>100 \mathrm{ng} / \mathrm{ML}$ ) was considered an indication of tobacco use. We assessed fruit and vegetable intake and fat quality using a combination of brief validated questionnaires and biomarkers. We measured fruit and vegetable intake using a 10-item food frequency screener that is highly correlated with fruit and vegetable intake on more intensive food frequency questionnaires (spearman rho 0.7) [50]; we also assessed serum carotenoids (Molecular Epidemiology and Biomarker Research Laboratory, University of Minnesota, Minneapolis, MN), which are correlated with servings of fruit and vegetable intake per day (i.e. a $27 \%$ relative increase corresponds to a 5 serving/day increase in reported intake). We assessed fat quality using a slightly modified version of a recently validated 20 -item questionnaire measuring intake of unsaturated, saturated, and trans fats[51]. On a subsample of participants ( $\mathrm{N}=298)$, we also assessed red blood cell membrane fatty acids as a biomarker of fatty acid intake (Molecular Epidemiology and Biomarker Research Laboratory, University of Minnesota, Minneapolis, MN). We measured physical activity using a modified version the RESIDE questionnaire, which provides a reliable estimate of the amount of moderate and intense physical activity per week [52, 53]. We then assessed steps per day using a pedometer that stores the previous 41 days of steps and aerobic steps (Omron HJ-720ITC, A Helping Hand HeathMed, Benicia, CA). 
Medication adherence (secondary outcome): Self-reported medication adherence was measured using the 8-item Morisky score, whose categorical assessment of high adherence ( $8=$ high, $6-7=$ medium adherence, $<6=$ low adherence) has been associated with better blood pressure control [54]. We focused on the proportion of individuals with high adherence and verified high adherence by correlating it with expected changes in blood pressure $(-4 \mathrm{mmHg})$ and cholesterol $(-20 \mathrm{mg} / \mathrm{dl})$ based on $50 \%$ of the standard change reported in meta-analyses of treatment trials. [55, 56]

Tertiary outcomes: To assess other variables of interest, we measured weight using electronic scales (Seca 770, Seca Corporation, Columbia, MD), and sent blood to a central laboratory for testing of serum creatinine, aspartate aminotransferase (AST), and hgba1c (Labcorp, Burlington, NC).

2.9.2. Acceptability of the Interventions-We assessed the acceptability of interventions to both participants and providers by asking participants how much they agreed that the intervention were useful, understandable, trustworthy, motivating, and important in helping them decide about CHD risk reduction. We also asked providers to report how much they agree that Heart to Health was helpful in motivating patients, understanding patients' values for risk reducing options, and getting counseling done. All answers were provided on a 5-point Likert scales, ranging from strongly agree to strongly disagree. Secondary measures of acceptability asked participants and providers to report on the helpfulness of various components of the intervention and to comment on the amount of information and time spent with the intervention. Providers were also asked to report on the usefulness of the intervention outside the research setting.

2.9.3. Cost-effectiveness-We assessed the cost per 1 absolute percentage point reduction in CHD risk from the participant, payer, and societal (sum of participant and payer) perspectives. Participant costs included participant time (assessed by the average hourly wage of US adults) and travel. Payer costs included labor and non-labor costs. Labor costs included market value for staff time associated with intervention delivery. Non-labor costs included costs for materials related to intervention delivery (business and appointment cards, postage, pedometers, cookbooks, binders and laptops for the web arm) and rent at the practices hosting the intervention.

\subsection{Sample size and power considerations}

With available resources, we planned to enroll 600 patients, including 500 with no known CVD who would form the primary sample for analysis and 100 with known CVD who would be included only in secondary analyses. Sample size and power estimates were obtained for mean changes within and mean differences between groups in the primary outcome (10-year predicted risk of CHD events at 4 month follow-up in those with no known CVD). Based on our prior work, we anticipated a 1.5 percentage point change in 10year predicted CHD risk from baseline to 4 months follow-up. Further, we expected that we might see as much as a 0.9 percentage point difference between groups in this outcome. Using a one-sided test, a standard deviation of 3.1 units, an $\alpha=0.05$, and an expected $10 \%$ attrition, we estimated that we needed 225 participants in each arm provide $>99 \%$ power to 
detect a within group difference in CHD risk. This sample size would then secondarily allow an $85 \%$ power to detect a 0.9 percentage point difference in predicted CHD risk between the counselor and web arms. The size of our secondary prevention subgroup (i.e. those with known CVD) was determined based on the sample size we deemed necessary to test the feasibility and acceptability of the intervention in this population.

\subsection{Quality control and intervention fidelity}

To ensure the quality of our conclusions, all research staff completed rigorous training on data collection and intervention delivery protocols. After an initial four-day training, followup trainings occurred at one and five months. We also audio-recorded and reviewed one of each of the 7 intervention counseling session (Sessions 1-7) per counselor. Counselors received feedback to standardize the content of the counseling session and ensure optimum counseling techniques consistent with principle of motivational interviewing.

\subsection{Analysis}

In this paper, we report descriptive statistics to compare the baseline characteristics of those randomized to the counselor and web-arms. For study outcomes, we will ultimately use the analysis plan that follows.

For analysis of our primary outcome, change in 10-year predicted CHD risk within intervention arms, we will use a one-sided paired t-test at each point in time. Following the example of others, we will exclude participants who develop a CVD event during the study period from our primary analysis [57-60]. All analyses will be intent-to-treat. Additionally, for the primary outcome, we plan to test multiple approaches for imputing missing followup data including last observations carried forward, multiple imputation, and consecutive $0.5 \%$ predicted risk increases to allow determination of any thresholds where conclusions might change.

To secondarily compare changes in predicted CHD risk between intervention arms at each point in time, we will use a linear regression model including baseline Framingham risk score and clinic as fixed effects. Inclusion of baseline scores as covariate is a more powerful test than comparing changes across time between two groups [61, 62]. We plan to adjust treatment comparison between groups for select baseline variables deemed relevant to behavior change a priori (age, race, educational achievement, and BMI) and for additional covariates that differ between intervention groups at baseline $(\mathrm{p}<0.10)$. Other secondary and tertiary analyses will examine variables of interest using paired t-tests or McNemar chisquare tests for within group comparisons and mixed effects models for between group differences, adjusting for covariates as described above.

To assess cost-effectiveness, we will calculate incremental cost-effectiveness ratios for the webarm compared with usual care, and for the counselor arm compared with the web arm. SAS version 9.3 will be used for all analyses, with $\mathrm{p} \leq .05$ considered significant. 


\section{Baseline Results}

In accordance with our recruitment procedures, we identified 2744 potentially eligible patients via chart review and obtained approval from clinicians for 1427 of them to participate (see Figure 1). Of these, 755 refused participation (largely due to lack of interest or perceived need or lack of transportation) and 39 could not be contacted. Thus, we enrolled 633 in the study.

After baseline risk assessment with standard methods across practices, 109 had Framingham risk scores of less than $10 \%$ and 524 remained eligible for participation. Of these, 490 were ultimately randomized within their risk stratum (390 with no known cardiovascular disease and 100 with it). These 490 patients were spread across the 5 participating practices (131 from Practice 1, 104 from Practice 2, 81 from Practice 3, 88 from Practice 4, and 78 from Practice 5) and were seen by 29 different clinicians.

Among those without prior cardiovascular disease ( $n=389)$, the main focus of our trial, 195 were randomized to the counselor arm and 195 to the web-arm. We subsequently determined that one was ineligible and excluded them from analyses. The remaining sample of 389 participants without known cardiovascular disease still provided $>99 \%$ power to detect a 1.5 percentage point change in CHD risk from baseline to 4 month follow-up (primary aim) and $80 \%$ power to detect a 0.9 percentage point difference in CHD risk between groups. Baseline characteristics in this group were evenly distributed (see Table 3) with no appreciable differences in age, race, income, education, health insurance, CHD risk, CHD risk factors, or self-reported risk reducing behaviors. Slightly more participants in the counselor arm were women and slightly more had a prescription drug plan, however, these differences were not statistically different.

Among those with prior cardiovascular disease ( $\mathrm{n}=100$; designed for hypothesis generation), 52 were randomized to the counselor arm and 48 to the web arm. Again, there were few clinically meaningful baseline differences (see Table 3). However, participants in the counselor arm were significantly more likely to live with a spouse or someone like a spouse (79\% versus $58 \%)$.

\section{Discussion}

In this paper, we described the research protocols we used for studying the comparative effectiveness of the same CHD prevention intervention delivered in two alternate formats: counsel-delivered or web-based. We also demonstrated the recruitment of a diverse sample of practices and participants. We anticipate that both interventions in this study will reduce CHD risk. Further, we anticipate that this study will provide critical information that can help clinicians, practices, and payers understand the tradeoffs in implementing various types of interventions, overall and in different patient populations and settings, and help them determine how to best use their limited resources.

The interventions evaluated in this study have several key features that should ensure reductions in CHD risk. First, they start with previously tested and successful lifestyle and medication interventions. Second, they combine these interventions, making it likely they 
will achieve greater risk reduction than either intervention alone. Third, each intervention starts with a decision aid that calculates CHD risk and models the achievable risk reduction possible with various combinations of lifestyle and medications; previous evidence suggests this is an effective motivator for risk reduction [44,63]. Finally, our study staff has been rigorously trained to ensure fidelity of intervention delivery.

This study also has key features that will ensure useful information for clinicians, practices, and payers making decisions about how to best implement interventions to reduce CHD risk. First, it is a rigorously designed randomized comparative effectiveness trial with attention to key methodological issues that would reduce selection bias, measurement bias, and confounding. Second, it examines a range of outcomes (e.g. effectiveness, acceptability, and cost-effectiveness) that are relevant to those making decisions about implementation of care. Third, it provides 12-month as well as 4 month follow-up data, allowing clinicians to make determinations about the impact of various implementation methods on long term health outcomes. Fourth, the diversity of practice types and resources in this study may allow inferences about moderators of intervention effect. Finally, the study's sample and practices, which are representative of the primary care delivered in North Carolina, should increase generalizability of findings.

With CHD prevention designated as a national priority and practice redesign high on the minds of many clinicians, practices, and payers, our study is poised to offer help to decision makers making critical decisions about how to best serve the needs of their patients and implement and sustain high quality CHD prevention in a cost effective manner. Future work will be important to expand our intervention to important subgroups not targeted by the current intervention (e.g. Latinos).

\section{Supplementary Material}

Refer to Web version on PubMed Central for supplementary material.

\section{Acknowledgements}

This research was supported by the U.S. Centers for Disease Control and Prevention (CDC), American Recovery and Reinvestment Act of 2009, Cooperative Agreement Number 1U48DP002658. This research was also supported in part by National Institutes of Health grant P30DK056350 to the UNC-CH Nutrition Obesity Research Center. The content is solely the responsibility of the authors. Authors would like to give special thanks to participating practices in the North Carolina Family Medicine Research Network and to the health counselors who delivered interventions at these sites (Kim Grimm, Beth Jenks, Taimur Khan, Sara Lindsley, Lauren Martin); without their kind participation, this work would not have been possible.

\section{References}

1. Lloyd-Jones D, Adams RJ, Brown TM, Carnethon M, Dai S, De Simone G, et al. Executive summary: heart disease and stroke statistics--2010 update: a report from the american heart association. Circulation. 121:948-954. [PubMed: 20177011]

2. Frieden TR, Berwick DM. The "Million Hearts" initiative--preventing heart attacks and strokes. N Engl J Med. 2011; 365:e27. [PubMed: 21913835]

3. Stampfer MJ, Hu FB, Manson JE, Rimm EB, Willett WC. Primary prevention of coronary heart disease in women through diet and lifestyle. N Engl J Med. 2000; 343:16-22. [PubMed: 10882764] 
4. Estruch R, Ros E, Salas-Salvado J, Covas MI, Corella D, Aros F, et al. Primary prevention of cardiovascular disease with a Mediterranean diet. N Engl J Med. 2013; 368:1279-1290. [PubMed: 23432189]

5. Gueyffier F, Froment A, Gouton M. New meta-analysis of treatment trials of hypertension: improving the estimate of therapeutic benefit. Journal of human hypertension. 1996; 10:1-8. [PubMed: 8642184]

6. Hall KM, Luepker RV. Is hypercholesterolemia a risk factor and should it be treated in the elderly. Am J Health Promot. 2000; 14:347-356. [PubMed: 11067569]

7. Pignone M, Phillips C, Mulrow C. Use of lipid lowering drugs for primary prevention of coronary heart disease: meta-analysis of randomised trials. BMJ. 2000; 321:983-986. [PubMed: 11039962]

8. Ridker PM, Danielson E, Fonseca FA, Genest J, Gotto AM Jr, Kastelein JJ, et al. Rosuvastatin to prevent vascular events in men and women with elevated C-reactive protein. N Engl J Med. 2008; 359:2195-2207. [PubMed: 18997196]

9. Sheridan S, Pignone M, Donahue K. Screening for high blood pressure: a review of the evidence for the U.S. Preventive Services Task Force. Am J Prev Med. 2003; 25:151-158. [PubMed: 12880884]

10. Staessen JA, Gasowski J, Wang JG, Thijs L, Den Hond E, Boissel JP, et al. Risks of untreated and treated isolated systolic hypertension in the elderly: meta-analysis of outcome trials. Lancet. 2000; 355:865-872. [PubMed: 10752701]

11. Walsh JM. Lipids in women: screening and treatment. J Am Med Womens Assoc. 2003; 58:240247. [PubMed: 14640255]

12. Executive Summary of The Third Report of The National Cholesterol Education Program (NCEP) Expert Panel on Detection, Evaluation, And Treatment of High Blood Cholesterol In Adults (Adult Treatment Panel III). JAMA. 2001; 285:2486-2497. [PubMed: 11368702]

13. Eriksson MK, Franks PW, Eliasson M. A 3-year randomized trial of lifestyle intervention for cardiovascular risk reduction in the primary care setting: the Swedish Bjorknas study. PLoS One. 2009; 4:e5195. [PubMed: 19365563]

14. Goldstein MG, Whitlock EP, DePue J. multiple behavioral risk factor interventions in primary care Summary of research evidence. Am J Prev Med. 2004; 27:61-79. [PubMed: 15275675]

15. Ma J, Berra K, Haskell WL, Klieman L, Hyde S, Smith MW, et al. Case management to reduce risk of cardiovascular disease in a county health care system. Arch Intern Med. 2009; 169:19881995. [PubMed: 19933961]

16. Glasgow RE, Bull SS, Piette JD, Steiner JF. Interactive behavior change technology. A partial solution to the competing demands of primary care. Am J Prev Med. 2004; 27:80-87. [PubMed: 15275676]

17. Noell J, Glasgow RE. Interactive technology applications for behavioral counseling: issues and opportunities for health care settings. Am J Prev Med. 1999; 17:269-274. [PubMed: 10606195]

18. Holtrop JS, Dosh SA, Torres T, Thum YM. The community health educator referral liaison (CHERL): a primary care practice role for promoting healthy behaviors. Am J Prev Med. 2008; 35:S365-s372. [PubMed: 18929983]

19. Krist AH, Woolf SH, Frazier CO, Johnson RE, Rothemich SF, Wilson DB, et al. An electronic linkage system for health behavior counseling effect on delivery of the 5A's. Am J Prev Med. 2008; 35:S350-s358. [PubMed: 18929981]

20. Ebrahim S, Beswick A, Burke M, Davey Smith G. Multiple risk factor interventions for primary prevention of coronary heart disease. Cochrane Database Syst Rev. 2006:CD001561. [PubMed: 17054138]

21. Sheridan SL, Viera AJ, Krantz MJ, Ice CL, Steinman LE, Peters KE, et al. The effect of giving global coronary risk information to adults: a systematic review. Arch Intern Med. 2010; 170:230239. [PubMed: 20142567]

22. Benner JS, Morrison MR, Karnes EK, Kocot SL, McClellan M. An evaluation of recent federal spending on comparative effectiveness research: priorities, gaps, and next steps. Health Aff (Millwood). 2010; 29:1768-1776. [PubMed: 20921474]

23. Slutsky JR, Clancy CM. Patient-centered comparative effectiveness research: essential for highquality care. Arch Intern Med. 2010; 170:403-404. [PubMed: 20212173] 
24. Bodenheimer T, Laing BY. The teamlet model of primary care. Ann Fam Med. 2007; 5:457-461. [PubMed: 17893389]

25. Sloane PD, Callahan L, Kahwati L, Mitchell CM. Development of a practice-based patient cohort for primary care research. Fam Med. 2006; 38:50-57. [PubMed: 16378259]

26. Kraschnewski JL, Keyserling TC, Bangdiwala SI, Gizlice Z, Garcia BA, Johnston LF, et al. Optimized probability sampling of study sites to improve generalizability in a multisite intervention trial. Prev Chronic Dis. 2010; 7:A10. [PubMed: 20040225]

27. Pignone M, Sheridan SL, Lee YZ, Kuo J, Phillips C, Mulrow C, et al. Heart to Heart: a computerized decision aid for assessment of coronary heart disease risk and the impact of riskreduction interventions for primary prevention. Prev Cardiol. 2004; 7:26-33. [PubMed: 15010625]

28. Ammerman AS, Keyserling TC, Atwood JR, Hosking JD, Zayed H, Krasny C. A randomized controlled trial of a public health nurse directed treatment program for rural patients with high blood cholesterol. Prev Med. 2003; 36:340-351. [PubMed: 12634025]

29. Keyserling TC, Ammerman AS, Davis CE, Chen Mok M, Garrett J, Simpson RA Jr. A randomized controlled trial of a physician-directed treatment program for low-income patients with high blood cholesterol: the Southeast Cholesterol Projec. Arch Fam Med. 1997; 6:135-145. [PubMed: 9075448]

30. Keyserling TC, Samuel Hodge CD, Jilcott SB, Johnston LF, Garcia BA, Gizlice Z, et al. Randomized trial of a clinic-based, community-supported, lifestyle intervention to improve physical activity and diet: the North Carolina enhanced WISEWOMAN project. Prev Med. 2008; 46:499-510. [PubMed: 18394692]

31. Keyserling TC, Samuel-Hodge CD, Ammerman AS, Ainsworth BE, Henriquez-Roldan CF, Elasy TA, et al. A randomized trial of an intervention to improve self-care behaviors of AfricanAmerican women with type 2 diabetes: impact on physical activity. Diabetes Care. 2002; 25:1576-1583. [PubMed: 12196430]

32. Hamer M, Chida Y. Active commuting and cardiovascular risk: a meta-analytic review. Prev Med. 2008; 46:9-13. [PubMed: 17475317]

33. Hu FB, Willett WC. Optimal diets for prevention of coronary heart disease. JAMA. 2002; 288:2569-2578. [PubMed: 12444864]

34. Mozaffarian D, Micha R, Wallace S. Effects on coronary heart disease of increasing polyunsaturated fat in place of saturated fat: a systematic review and meta-analysis of randomized controlled trials. PLoS medicine. 2010; 7:e1000252. [PubMed: 20351774]

35. Mozaffarian D, Rimm EB. Fish intake, contaminants, and human health: evaluating the risks and the benefits. JAMA. 2006; 296:1885-1899. [PubMed: 17047219]

36. Oh K, Hu FB, Manson JE, Stampfer MJ, Willett WC. Dietary fat intake and risk of coronary heart disease in women: 20 years of follow-up of the nurses' health study. Am J Epidemiol. 2005; 161:672-679. [PubMed: 15781956]

37. Pereira MA, O'Reilly E, Augustsson K, Fraser GE, Goldbourt U, Heitmann BL, et al. Dietary fiber and risk of coronary heart disease: a pooled analysis of cohort studies. Arch Intern Med. 2004; 164:370-376. [PubMed: 14980987]

38. Zheng H, Orsini N, Amin J, Wolk A, Nguyen VT, Ehrlich F. Quantifying the dose-response of walking in reducing coronary heart disease risk: meta-analysis. European journal of epidemiology. 2009; 24:181-192. [PubMed: 19306107]

39. Sheridan SL, Draeger LB, Pignone MP, Keyserling TC, Simpson RJ Jr, Rimer B, et al. A randomized trial of an intervention to improve use and adherence to effective coronary heart disease prevention strategies. BMC Health Serv Res. 2011; 11:331. [PubMed: 22141447]

40. Hernandez-Diaz S, Garcia Rodriguez LA. Cardioprotective aspirin users and their excess risk of upper gastrointestinal complications. BMC medicine. 2006; 4:22. [PubMed: 16987411]

41. Hippisley-Cox J, Coupland C. Unintended effects of statins in men and women in England and Wales: population based cohort study using the QResearch database. Bmj. 2010; 340:c2197. [PubMed: 20488911]

42. Baigent C, Blackwell L, Collins R, Emberson J, Godwin J, Peto R, et al. Aspirin in the primary and secondary prevention of vascular disease: collaborative meta-analysis of individual participant data from randomised trials. Lancet. 2009; 373:1849-1860. [PubMed: 19482214] 
43. Wolf PA, D'Agostino RB, Belanger AJ, Kannel WB. Probability of stroke: a risk profile from the Framingham Study. Stroke; a journal of cerebral circulation. 1991; 22:312-318.

44. Sheridan SL, Shadle J, Simpson RJJ, Pignone MP. The impact of a decision aid about heart disease prevention on patients- discussions with their doctor and their plans for prevention: a pilot randomized trial. BMC Health Serv Res. 2006; 6:121. [PubMed: 17005051]

45. Anderson KM, Odell PM, Wilson PW, Kannel WB. Cardiovascular disease risk profiles. Am Heart J. 1991; 121:293-298. [PubMed: 1985385]

46. Pearson TA. New tools for coronary risk assessment: what are their advantages and limitations. Circulation. 2002; 105:886-892. [PubMed: 11854132]

47. Booth GL, Kapral MK, Fung K, Tu JV. Relation between age and cardiovascular disease in men and women with diabetes compared with non-diabetic people: a population-based retrospective cohort study. Lancet. 2006; 368:29-36. [PubMed: 16815377]

48. Haffner SM, Lehto S, Ronnemaa T, Pyorala K, Laakso M. Mortality from coronary heart disease in subjects with type 2 diabetes and in nondiabetic subjects with and without prior myocardial infarction. N Engl J Med. 1998; 339:229-234. [PubMed: 9673301]

49. Antithrombotic Trialists C, Baigent C, Blackwell L, Collins R, Emberson J, Godwin J, et al. Aspirin in the primary and secondary prevention of vascular disease: collaborative meta-analysis of individual participant data from randomised trials. Lancet. 2009; 373:1849-1860. [PubMed: 19482214]

50. Block G, Gillespie C, Rosenbaum EH, Jenson C. A rapid food screener to assess fat and fruit and vegetable intake. Am J Prev Med. 2000; 18:284-288. [PubMed: 10788730]

51. Kraschnewski JL, Gold AD, Gizlice Z, Johnston LF, Garcia BA, Samuel-Hodge CD, et al. Development and Evaluation of a Brief Questionnaire to Assess Dietary Fat Quality in Lowincome Overweight Women in the Southern United States. Journal of nutrition education and behavior. 2013

52. Craig CL, Marshall AL, Sjostrom M, Bauman AE, Booth ML, Ainsworth BE, et al. International physical activity questionnaire: 12-country reliability and validity. Med Sci Sports Exerc. 2003; 35:1381-1395. [PubMed: 12900694]

53. Giles-Corti B, Timperio A, Cutt H, Pikora TJ, Bull FC, Knuiman M, et al. Development of a reliable measure of walking within and outside the local neighborhood: RESIDE's Neighborhood Physical Activity Questionnaire. Prev Med. 2006; 42:455-459. [PubMed: 16574208]

54. Morisky DE, Ang A, Krousel-Wood M, Ward HJ. Predictive validity of a medication adherence measure in an outpatient setting. Journal of clinical hypertension (Greenwich, Conn). 2008; 10:348-354.

55. Law MR, Wald NJ, Morris JK, Jordan RE. Value of low dose combination treatment with blood pressure lowering drugs: analysis of 354 randomised trials. BMJ. 2003; 326:1427. [PubMed: 12829555]

56. Law MR, Wald NJ, Rudnicka AR. Quantifying effect of statins on low density lipoprotein cholesterol, ischaemic heart disease, and stroke: systematic review and meta-analysis. Bmj. 2003; 326:1423. [PubMed: 12829554]

57. Appel LJ, Sacks FM, Carey VJ, Obarzanek E, Swain JF, Miller ERr, et al. Effects of protein, monounsaturated fat, and carbohydrate intake on blood pressure and serum lipids: results of the OmniHeart randomized trial. JAMA. 2005; 294:2455-2464. [PubMed: 16287956]

58. Edelman D, Oddone EZ, Liebowitz RS, Yancy WSJ, Olsen MK, Jeffreys AS, et al. A multidimensional integrative medicine intervention to improve cardiovascular risk. J Gen Intern Med. 2006; 21:728-734. [PubMed: 16808774]

59. Grover SA, Lowensteyn I, Joseph L, Kaouache M, Marchand S, Coupal L, et al. Patient knowledge of coronary risk profile improves the effectiveness of dyslipidemia therapy: the CHECK-UP study: a randomized controlled trial. Arch Intern Med. 2007; 167:2296-2303. [PubMed: 18039987]

60. Krones T, Keller H, Sonnichsen A, Sadowski EM, Baum E, Wegscheider K, et al. Absolute cardiovascular disease risk and shared decision making in primary care: a randomized controlled trial. Ann Fam Med. 2008; 6:218-227. [PubMed: 18474884]

61. Vickers AJ, Altman DG. Statistics notes: Analysing controlled trials with baseline and follow up measurements. BMJ. 2001; 323:1123-1124. [PubMed: 11701584] 
62. Frison L, Pocock SJ. Repeated measures in clinical trials: analysis using mean summary statistics and its implications for design. Stat Med. 1992; 11:1685-1704. [PubMed: 1485053]

63. Sheridan SL, Behrend L, Vu MB, Meier A, Griffith JM, Pignone MP. ndividuals' responses to global CHD risk: A focus group study. Patient Educ Couns. 2009 
- 755 refused

- 39 no contact

- 847 no provider referral
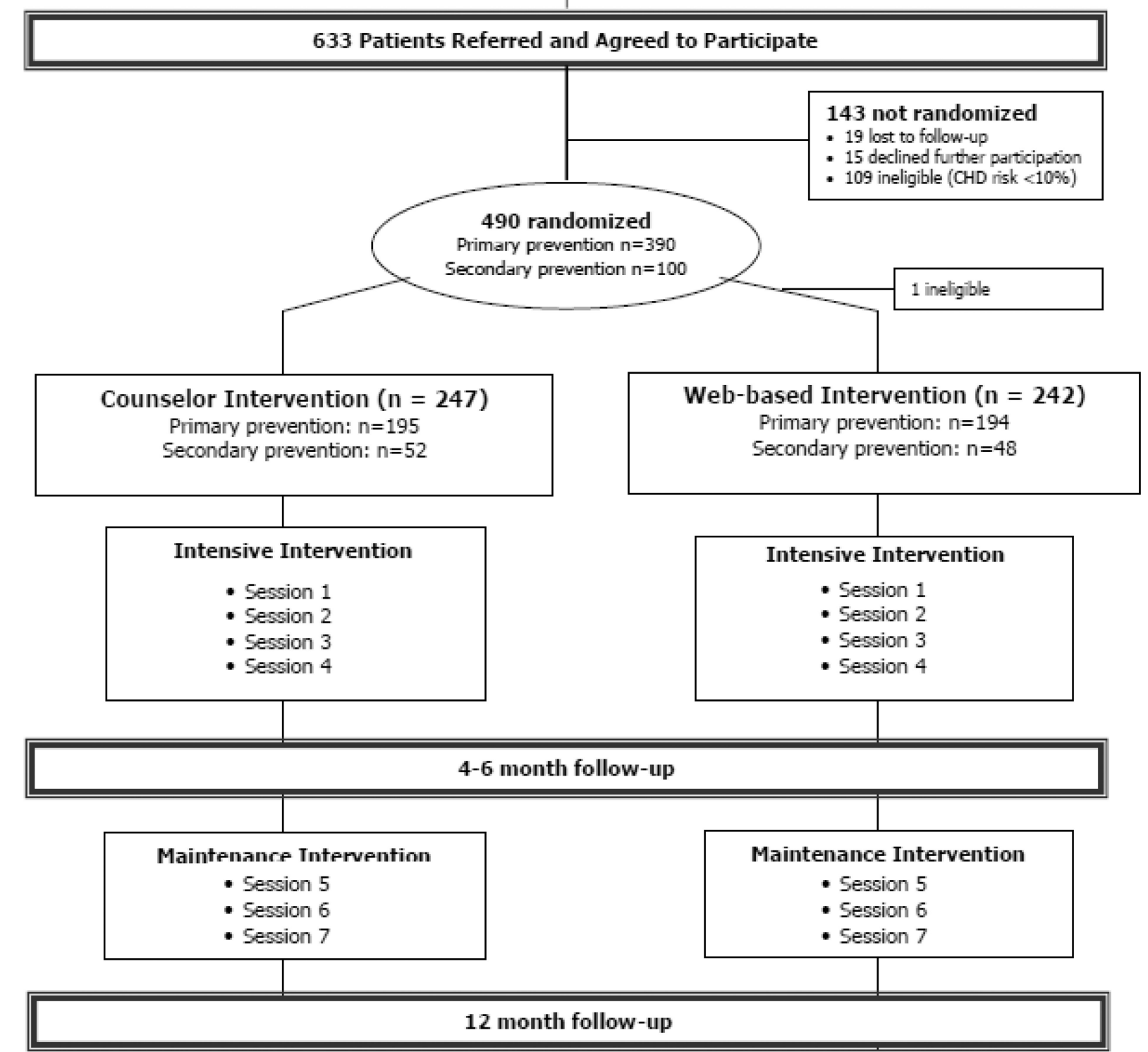

Figure 1.

Study flow diagram 


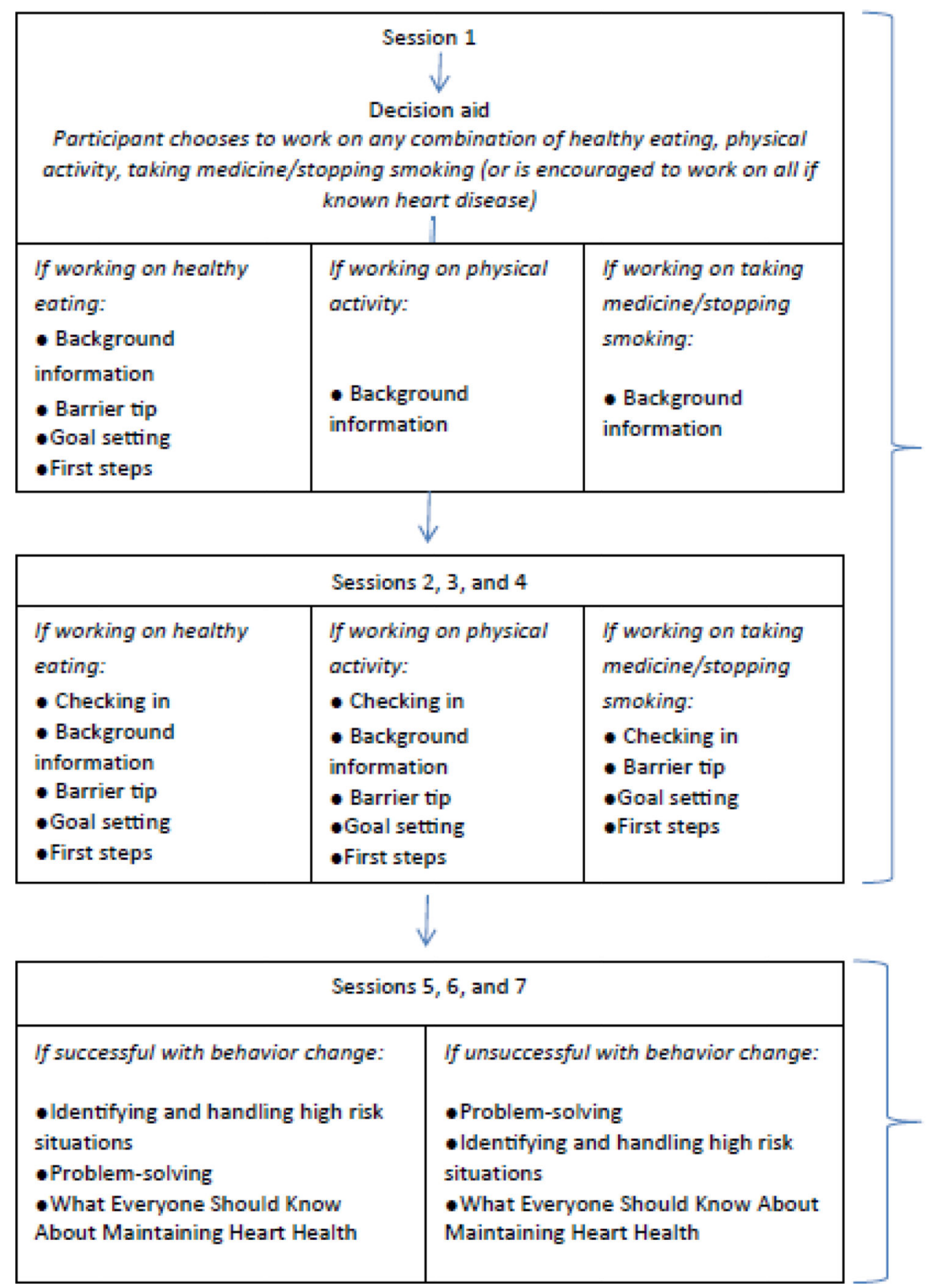

Intensive Intervention 4 monthly contacts; Up to 1 hour each

Figure 2.

Intervention flow diagram 


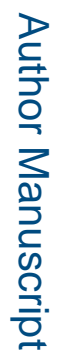

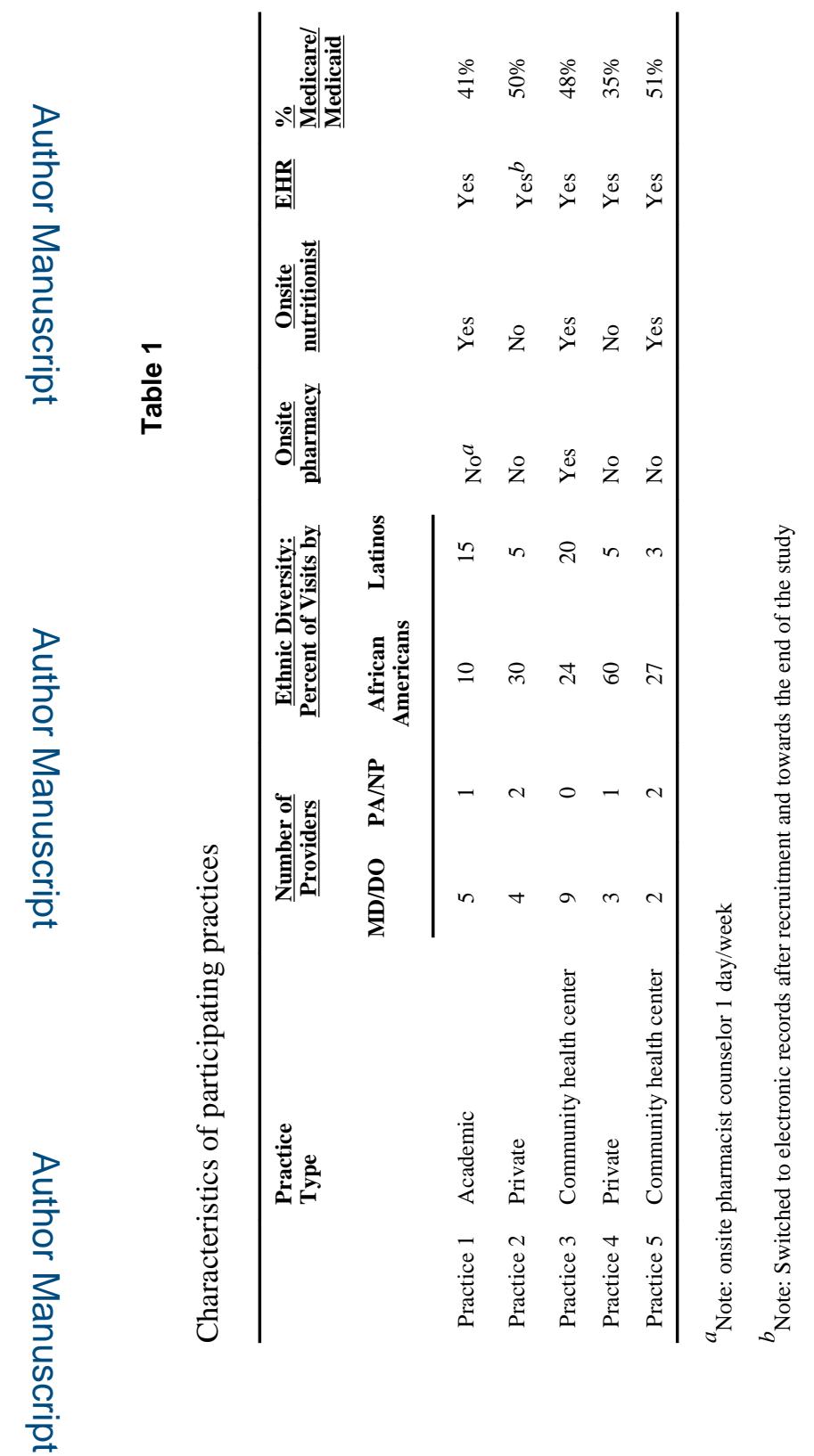

Contemp Clin Trials. Author manuscript; available in PMC 2014 November 01. 
Table 2

\section{Overview of measures}

\begin{tabular}{|c|c|c|}
\hline Measure & Measurement Detail & Lab \\
\hline \multicolumn{3}{|c|}{ Efficacy Measures } \\
\hline $\begin{array}{l}\text { 10-year Predicted CHD Risk } \\
\text { (Primary) }\end{array}$ & $\begin{array}{l}\text { - Framingham Risk Equation predicting angina, MI, CHD } \\
\text { death [44] }\end{array}$ & \\
\hline Blood pressure & $\begin{array}{l}\text { Average of } 3 \text { measurements taken at } 1 \text { minute intervals } \\
\text { using oscillometric automatic monitor (Omron } \\
\text { HEM-907) }\end{array}$ & \\
\hline Cholesterol (Total, HDL, LDL) & $\begin{array}{ll}\text { - } & \text { Serum total and HDL cholesterol } \\
\text { - } & \text { Direct LDL }\end{array}$ & LabCorp, Burlington NC \\
\hline Aspirin use & $\begin{array}{ll}\text { - } & \text { Single item self-report (yes/no) } \\
\text { - } & \text { Serum thromboxane if reported use (levels }<500 \text { confirm } \\
\text { use) }\end{array}$ & $\begin{array}{l}\text { Laboratory for Clinical } \\
\text { Biochemistry Research, } \\
\text { University of Vermont }\end{array}$ \\
\hline Smoking status & $\begin{array}{l}\text { - Single item self-report (>100 cigarettes: yes/no) } \\
\text { - Urinary cotinine if reported quitting (3 or higher } \\
\text { confirms smoking) }\end{array}$ & Jant Pharmacal; Encino, $\mathrm{CA}^{b}$ \\
\hline Fruit and vegetable intake & $\begin{array}{l}\text { - } 10 \text {-item Block Screener [48] } \\
\text { - } \quad \text { Serum carotenoids ( } 27 \% \text { relative increase corresponds to } \\
5 \text { servings/day) }\end{array}$ & $\begin{array}{l}\text { Molecular Epidemiology and } \\
\text { Biomarker Research Laboratory, } \\
\text { University of Minnesota, } \\
\text { Minneapolis, MN }\end{array}$ \\
\hline Dietary fat quality & $\begin{array}{ll}\text { - } & \text { 20-item fat screener [49] } \\
\text { - } & \begin{array}{l}\text { Red blood cell membrane fatty acids in random } \\
\text { subsample }(\mathrm{n}=298)\end{array}\end{array}$ & $\begin{array}{l}\text { Molecular Epidemiology and } \\
\text { Biomarker Research Laboratory, } \\
\text { University of Minnesota, } \\
\text { Minneapolis, MN }\end{array}$ \\
\hline Physical activity & $\begin{array}{ll}\text { - } & \text { Modified RESIDE questionnaire [50,51] } \\
\text { - } & \text { Pedometer steps/day using Omron HJ-720ITC }\end{array}$ & \\
\hline Medication adherence & $\begin{array}{l}\text { - } \\
\text {-item Morisky scale [52] } \\
\text { Change in blood pressure }(-4 \mathrm{mmHg}) \text { and cholesterol } \\
(-20 \mathrm{mg} / \mathrm{dL})[53,54]\end{array}$ & \\
\hline \multicolumn{3}{|c|}{ Acceptability Measures } \\
\hline Acceptability of Intervention & $\begin{array}{l}\text { 6-item internally developed score assessing overall } \\
\text { acceptability to patients } \\
\text { 7-item internally developed score assessing overall } \\
\text { acceptability to providers } \\
\text { - Secondary measures assessing the helpfulness of the } \\
\text { intervention, the amount of information and time spent } \\
\text { with various intervention components, and for providers } \\
\text { the usefulness of the intervention outside the research } \\
\text { context }\end{array}$ & \\
\hline \multicolumn{3}{|c|}{ Cost-Effectiveness Measures } \\
\hline Cost-Effectiveness & $\begin{array}{l}\text { Incremental cost for } 1 \% \text { reduction in CHD risk from } \\
\text { provider, payor, and societal perspectives }\end{array}$ & \\
\hline
\end{tabular}


$a_{\text {In those with no known CVD only }}$

$b_{\text {Tested at the point of care using supplies provided by Jant Pharmacal }}$ 


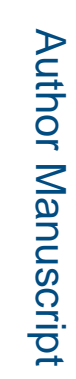

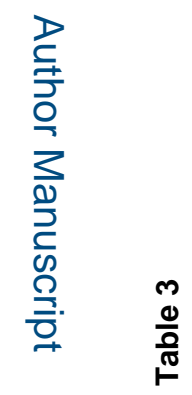

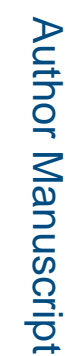

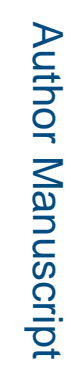

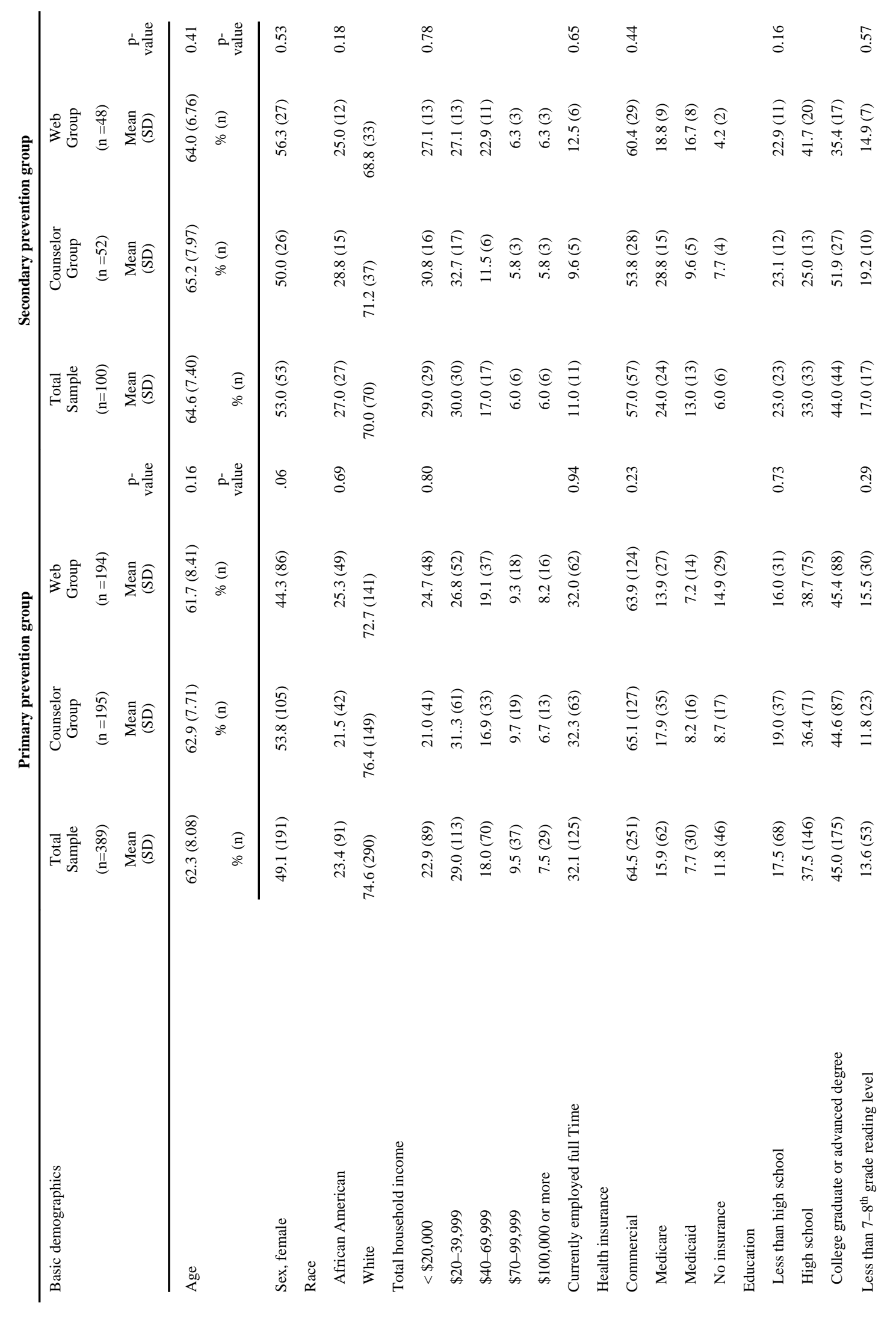

Contemp Clin Trials. Author manuscript; available in PMC 2014 November 01. 


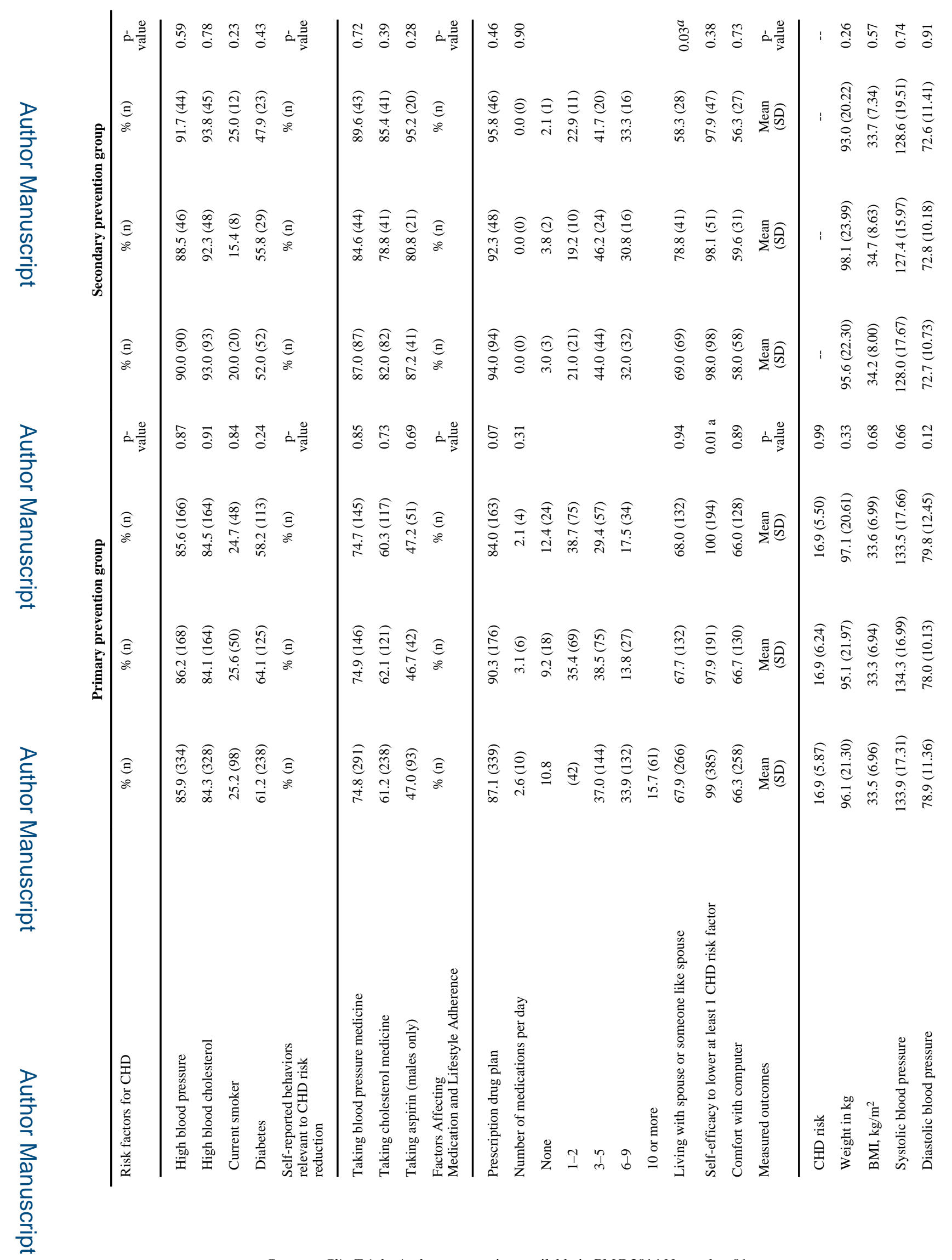

Contemp Clin Trials. Author manuscript; available in PMC 2014 November 01. 


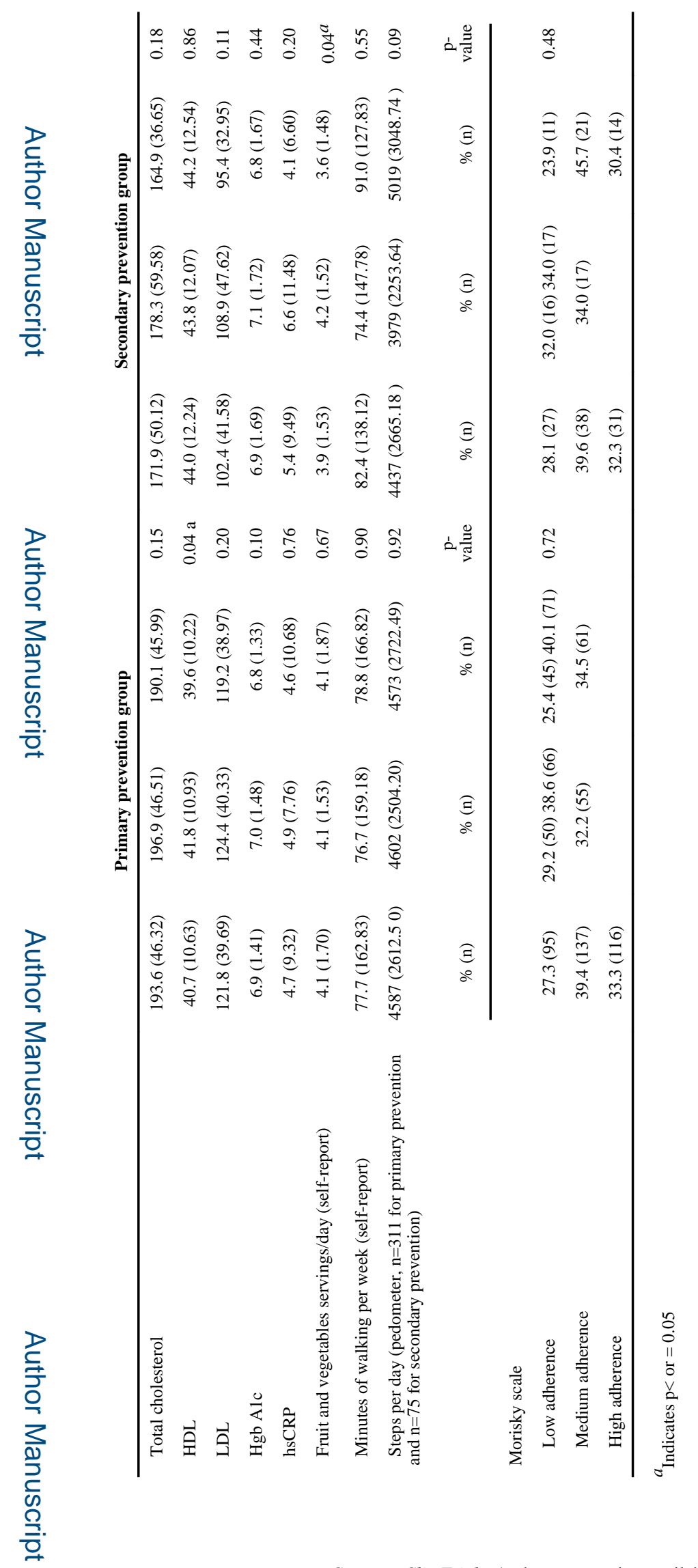

